\title{
Relationships of Pelvic Vein Diameter and Reflux with Clinical Manifestations of Pelvic Venous Disorder
}

\author{
Sergey Gavrilov *(1), Anatoly Karalkin, Nadezhda Mishakina, Oksana Efremova and Anastasia Grishenkova
}

Citation: Gavrilov, S.; Karalkin, A.; Mishakina, N.; Efremova, O.; Grishenkova, A. Relationships of Pelvic Vein Diameter and Reflux with Clinical Manifestations of Pelvic Venous Disorder. Diagnostics 2022, 12, 145. https://doi.org/10.3390/ diagnostics 12010145

Academic Editor: Romaric Loffroy

Received: 12 December 2021

Accepted: 6 January 2022

Published: 7 January 2022

Publisher's Note: MDPI stays neutral with regard to jurisdictional claims in published maps and institutional affiliations.

Copyright: (C) 2022 by the authors. Licensee MDPI, Basel, Switzerland. This article is an open access article distributed under the terms and conditions of the Creative Commons Attribution (CC BY) license (https:// creativecommons.org/licenses/by/ $4.0 /)$.
Savelyev University Surgical Clinic, Pirogov Russian National Research Medical University, 10/5 Leninsky Prospect, 119049 Moscow, Russia; olittosg@gmail.com (A.K.); mishakina.78@mail.ru (N.M.); lpl2@yandex.ru (O.E.); ngrishenkova@rambler.ru (A.G.)

* Correspondence: gavriloffsg@mail.ru; Tel.: +7-(916)-929-99-47

\begin{abstract}
The causes of chronic pelvic pain (CPP) in patients with pelvic venous disorder (PeVD) are not completely understood. Various authors consider dilation of pelvic veins (PeVs) and pelvic venous reflux (PVR) as the main mechanisms underlying symptomatic forms of PeVD. The aim of this study was to assess relationships of pelvic vein dilation and PVR with clinical manifestations of PeVD. This non-randomized comparative cohort study included 80 female patients with PeVD who were allocated into two groups with symptomatic $(n=42)$ and asymptomatic $(n=38)$ forms of the disease. All patients underwent duplex scanning and single-photon emission computed tomography (SPECT) of PeVs with in vivo labeled red blood cells (RBCs). The PeV diameters, the presence, duration and pattern of PVR in the pelvic veins, as well as the coefficient of pelvic venous congestion $\left(\mathrm{C}_{\mathrm{PVC}}\right)$ were assessed. Two groups did not differ significantly in pelvic vein diameters (gonadal veins (GVs): $7.7 \pm 1.3$ vs. $8.5 \pm 0.5 \mathrm{~mm}$; parametrial veins (PVs): $9.8 \pm 0.9$ vs. $9.5 \pm 0.9 \mathrm{~mm}$; and uterine veins (UVs): $5.6 \pm 0.2$ vs. $5.5 \pm 0.6 \mathrm{~mm}$ ). Despite this, $\mathrm{C}_{\mathrm{PVC}}$ was significantly higher in symptomatic versus asymptomatic patients $(1.9 \pm 0.4$ vs. $0.7 \pm 0.2$, respectively; $p=0.008)$. Symptomatic patients had type II or III PVR, while asymptomatic patients had type I PVR. The reflux duration was found to be significantly greater in symptomatic versus asymptomatic patients (median and interquartile range: $4.0[3.0 ; 5.0]$ vs. $1.0[0 ; 2.0]$ s for GVs, $p=0.008 ; 4.0$ [3.0; 5.0] vs. $1.1[1.0 ; 2.0]$ s for PVs, $p=0.007$; and $2.0[2.0 ; 3.0]$ vs. $1.0[1.0 ; 2.0] \mathrm{s}$ for UVs, $p=0.04)$. Linear correlation analysis revealed a strong positive relationship (Pearson's $r=0.78 ; p=0.007$ ) of CPP with the PVR duration but not with vein diameter. The grade of $\mathrm{PeV}$ dilation may not be a determining factor in CPP development in patients with PeVD. The presence and duration of reflux in the pelvic veins were found to be predictors of the development of symptomatic PeVD.
\end{abstract}

Keywords: pelvic venous disorder; pelvic pain; pelvic vein diameter; pelvic venous reflux; duplex ultrasound; single-photon emission computed tomography of pelvic veins

\section{Introduction}

The dilation of pelvic (parametrial, uterine and gonadal) veins and reflux in them are associated with the presence of chronic pelvic pain (CPP) in 60-76\% of patients with pelvic venous disease (PeVD) [1-5]. According to the UIP consensus document, the dilation of pelvic veins (PeVs) is defined as an increase in their diameter of greater than $5 \mathrm{~mm}$, and the pelvic venous reflux (PVR) is considered pathological if it lasts for greater than $1 \mathrm{~s}$ [2]. PVR of greater than $2 \mathrm{~s}$ in several pelvic venous collecting pools was found to be associated with severe CPP [4]. Some authors [6] also pointed out a relationship between the degree of PeV dilation and clinical manifestations of PeVD. Ganeshan et al. reported that $\mathrm{PeV}$ dilation of greater than $8 \mathrm{~mm}$ can be a criterion for the diagnosis of PeVD [6]. However, a study by Dos Santos et al. has demonstrated that the diameter of ovarian veins is not a predictor of reflux in them [7]. Whiteley et al. have repeatedly pointed out that the presence of reflux and its duration are major determinants of the severity of the 
disease and serve as an indication for intervention on PeVs [8-11]. However, in 2021, Szary et al. presented a classification of ovarian veins system insufficiency based on the degree of their dilatation [12]. These contradictory opinions indicate the need for further research to identify factors determining clinical manifestations of PeVD, primarily CPP. The present study was aimed at investigating relationships between pelvic vein dilation, PVR, and the presence and severity of clinical manifestations of PeVD.

\section{Materials and Methods}

This non-randomized comparative cohort study included 80 female patients aged 23 to 42 years (interquartile range: 9 years) with PeVD. Eligible for inclusion were women aged from 18 to 45 years with pelvic varicose veins diagnosed by DUS and without post-thrombotic syndrome (PTS), pregnancy, virgo intacta status (a contraindication for transvaginal DUS), as well as disorders that can be accompanied by CPP. The study was approved by the local Ethics Committee of the University, and all patients signed an informed consent form before entering the study.

The patients were allocated into two groups based on the results of clinical examination, DUS of the pelvic veins and consultations of related specialists (gynecologist, urologist and neurologist). The first group $(\mathrm{n}=42)$ included patients with symptoms and signs of PeVD (CPP, heaviness in hypogastrium, dyspareunia, dysuria, vulvar varicosities). The intensity of pain syndrome was evaluated using a visual analogue scale (VAS) ranging from 0 to 10 scores (where 0 is no pain and 10 is maximum pain) and was graded as mild $(1-4)$, moderate $(5-6)$ or severe $(7-10)$. The second group $(n=38)$ consisted of patients without clinical manifestations of PeVD, in whom pelvic varicose veins were identified accidentally during a routine gynecological ultrasound examination of the pelvic organs or during examination for chronic venous disease (CVD) of the lower extremities. All patients underwent DUS and single-photon emission computed tomography (SPECT) of the pelvic veins with in vivo labeled red blood cells (RBCs). The study design is shown in Figure 1.

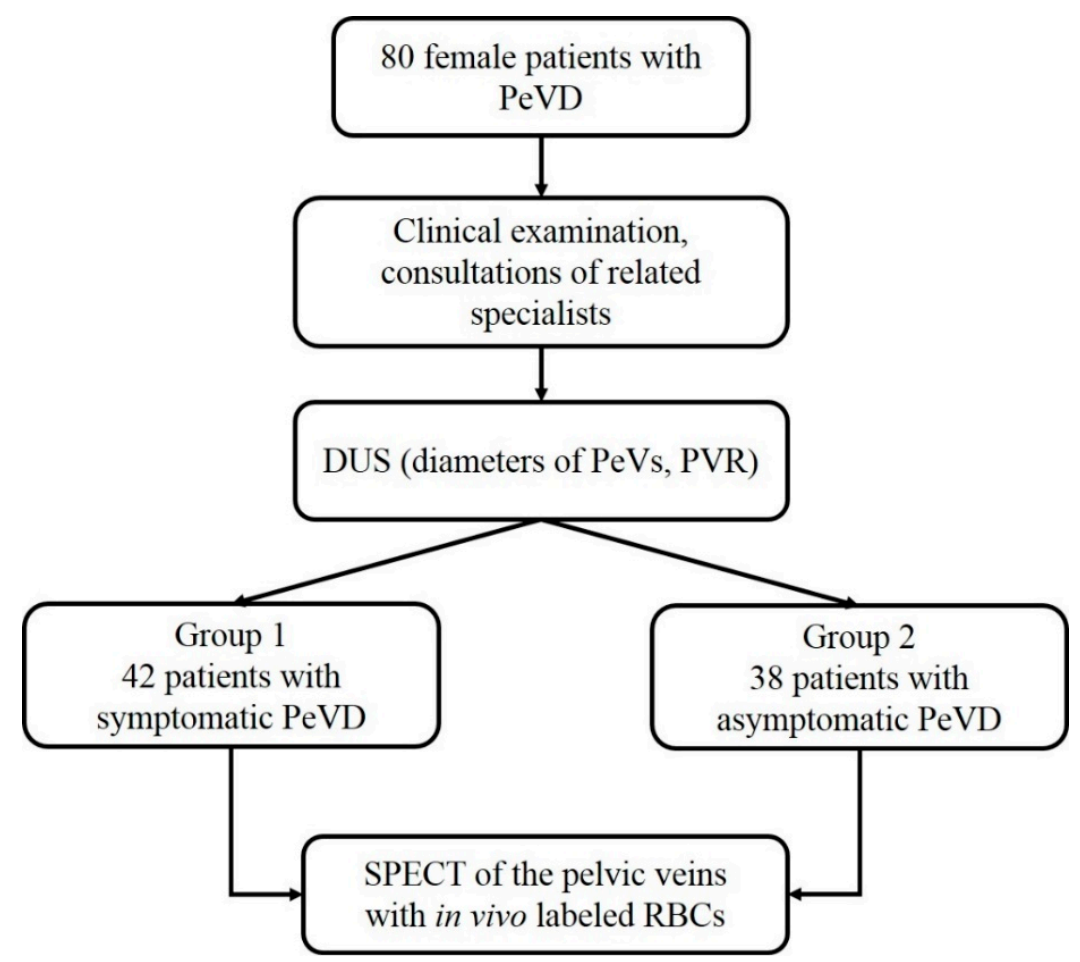

Figure 1. Study design. Abbreviations: PeVD, pelvic venous disorder; DUS, duplex ultrasonography; PeVs, pelvic veins; PVR, pelvic venous reflux; SPECT, single-photon emission computed tomography; RBCs, red blood cells. 


\subsection{Assessment of the Pelvic Veins}

Ultrasound examinations of the pelvic and lower limb veins were performed using Esaote MyLab Class C (Esaote, Genova, Italy) devices. The examination protocol included a sequential assessment of the status of superficial and deep veins of the lower extremities, perineal veins, pelvic (parametrial, uterine, gonadal) veins, iliac veins, inferior vena cava and renal veins. During the ultrasound studies, breathing (Valsalva maneuver) and compression tests were used to detect blood reflux in the veins of the lower extremities, perineum and pelvis. An increase in the diameter of the pelvic veins (i.e., only parametrial, uterine and gonadal veins) of more than $5 \mathrm{~mm}$ was considered pathological [2]. Reflux was defined as retrograde flow lasting for more than $1 \mathrm{~s}$ in PeVs and deep veins of the lower extremities $[2,5]$.

DUS of the veins of the lower extremities and perineal veins was performed by standard protocol using a 7.5-13 MHz transducer in the supine and standing position of the patient and included an assessment of the vein patency and diameter, the presence of pathological reflux in the sapheno-femoral and sapheno-popliteal junctions, trunks of the great (GSV) and small (SSV) saphenous veins, and veins of the labia majora (vulvar veins), as well as the presence of retrograde blood flow in the ostial tributaries of the GSV (superficial epigastric, superficial circumflex iliac, superficial external pudendal veins).

Transabdominal duplex ultrasound (TADUS) of the iliac veins, inferior vena cava, renal and gonadal veins was performed using convex (3-5 MHz) and linear (3-18 MHz) transducers in the patient's supine and half-sitting (with trunk raised to $45^{\circ}$ ) positions. The patency and diameters of the external, internal and common iliac veins, inferior vena cava and renal veins were assessed. The maximum blood flow velocity in the iliac and left renal veins was measured, and the presence and duration of reflux in the internal iliac vein (IIV) and GVs were assessed. The left renal vein status was studied using transverse and longitudinal scanning of the vessel, the left renal vein diameters in the projection of its compression by the superior mesenteric artery, in the area of the renal hilum, and between the superior mesenteric artery and the renal hilum were measured, and maximum blood flow velocity was determined at the site of its compression and in the area of the renal hilum [13,14].

Transvaginal duplex ultrasound (TVDUS) of the pelvic veins was performed using endovaginal micro-convex transducers with a frequency of 3-9 MHz and 3.5-10 MHz in the patient's supine, half-sitting (with trunk raised to $45^{\circ}$ ) and half-standing positions $[4,9,11]$. The patency and diameter of the parametrial, uterine and gonadal veins (PVs, UVs and GVs, respectively) and IIV, as well as the presence and duration of reflux in these vessels were evaluated. The study of the IIV tributaries with identification of retrograde blood flow in them was not carried out due to inconclusiveness and low reproducibility of these parameters with DUS.

PVR was assessed using the previously developed classification, with types I (mild), II (moderate) and III (severe) PVR corresponding to the reflux duration of 1-2 s, 2.1-5 s and greater than $5 \mathrm{~s}$ (or with spontaneous reflux in PeVs without exercise load), accordingly [4].

SPECT of the pelvic veins with in vivo labeled red blood cells was performed for radionuclide assessment of PeVs and the degree of pelvic venous congestion (PVC). The Discovery NM/CT 670 (GE, St, Boston, MA, USA) and Philips Forte (Philips Healthcare, Best, The Netherlands) imaging systems were used [15]. The Perfotech solution for the in vivo labeling of RBCs was injected in the cubital vein in a dose of $2 \mathrm{~mL}$, followed by $99 \mathrm{mTc}$-pertechnetate injection $20 \mathrm{~min}$ later. SPECT was performed at $20 \mathrm{~min}$ postinjection using a $360^{\circ}$ circular orbit rotation of gamma detector for obtaining images of the distribution of labeled RBCs in the pelvic veins. In a healthy individual, no or only negligible accumulation of a radiopharmaceutical (RPH) is identified in the OVs, PVs and UVs, while in PeVD patients the accumulation of RPH in PVs and UVs along with contrasting of GVs (most often of the left vein) is observed.

With the use of computer equipment for gamma camera, the radiation from RPH was measured in the regions of interest (in counts per second). For an objective assessment 
of venous congestion in the uterus and parametrium, the coefficient of pelvic venous congestion $\left(\mathrm{C}_{\mathrm{PVC}}\right)$ was calculated as the ratio of counts from "parametrial veins" to counts from the "common iliac vein".

The activity of labeled RBCs in the common iliac vein is the most stable parameter. The activity of RBC-phosphate-pertechnetate complex in venous plexuses depends on the degree of their dilation, the presence of reflux and, thus, the degree of blood deposition in them. In healthy individuals, $\mathrm{C}_{\mathrm{PVC}}$ does not exceed 0.5 , while in $\mathrm{PeV}$ dilation and reflux, the labeled RBCs are accumulated in the dilated pelvic venous collecting pools, resulting in a significant increase in $\mathrm{C}_{\mathrm{PVC}}$. The PVC severity was assessed by the $\mathrm{C}_{\mathrm{PVC}}$ increase as follows: $0.5-1.0$, grade I; $1.1-1.5$, grade II, and $\geq 1.5$, grade III.

\subsection{Statistical Methods}

Statistical analysis was performed using Microsoft Excel (Microsoft Corp., Redmond, WA, USA), Statistica 10 software (StatSoft, Tibko, Palo Alto, CA, USA) and VassarStats online calculator (open source online project; http:/ / vassarstats.net/ (accessed on 22 November 2021)). We present continuous variables as either mean (SD) or median (interquartile range) as appropriate, and categorical variables as number and frequency (percentage of group). Comparisons were made using the Student's t-test and Mann-Whitney test, where appropriate, for quantitative variables, and the Chi-square test for categorical variables. Differences were considered statistically significant at $p<0.05$. To study linear relationships between different continuous variables with normal distribution, the Pearson's correlation coefficient was used.

\section{Results}

The study groups did not differ significantly in demographic and clinical characteristics, except in the lower body mass index (BMI) and the rate of varicose veins of the lower extremities (VVLE) in symptomatic as compared to asymptomatic patients (Table 1). Significant differences between study groups were revealed using ultrasound and radionuclide studies.

Table 1. Demographic and clinical characteristic of study participants $(\mathrm{N}=80)$.

\begin{tabular}{|c|c|c|c|}
\hline Variable & $\begin{array}{l}\text { Symptoms of } \\
\text { PeVD }(n=42)\end{array}$ & $\begin{array}{l}\text { No Symptoms of } \\
\text { PeVD }(n=38)\end{array}$ & $p$ Value \\
\hline Age, mean $\pm S D$, years & $32.5 \pm 1.4$ & $33.3 \pm 1.2$ & 0.6 \\
\hline $\mathrm{BMI}$, mean $\pm \mathrm{SD}, \mathrm{kg} / \mathrm{m}^{2}$ & $21.1 \pm 1.2$ & $24.5 \pm 0.8$ & 0.02 \\
\hline PeVD duration, mean $\pm S D$, years & $4.2 \pm 2.3$ & $3.3 \pm 1.8$ & 0.4 \\
\hline $\mathrm{CPP}$, mean $\pm \mathrm{SD}$, VAS scores & $7.4 \pm 1.6$ & 0 & n.a. \\
\hline Dyspareunia, mean $\pm S D$, VAS scores & $6.3 \pm 0.9$ & 0 & n.a. \\
\hline Heaviness in hypogastrium, n (\%) & $42(100)$ & 0 & n.a. \\
\hline Dysuria, n (\%) & $15(36)$ & 0 & n.a. \\
\hline Vulvar varicosities, n (\%) & $11(26)$ & 0 & n.a. \\
\hline VVLE, $\mathrm{n}(\%)$ & $6(14)$ & $17(45)$ & $<0.01$ \\
\hline CVD of class 1 CEAP, $n(\%)$ & $15(36)$ & $11(29)$ & $>0.01$ \\
\hline Number of pregnancies, $\mathrm{n}$ & $2-4$ & $2-4$ & n.a. \\
\hline Number of births, $\mathrm{n}$ & $1-3$ & $1-3$ & n.a. \\
\hline Small uterine fibroids, $\mathrm{n}(\%)$ & $3(7)$ & $4(11)$ & $>0.01$ \\
\hline Polycystic ovaries, n (\%) & $5(12)$ & $3(8)$ & $>0.01$ \\
\hline Chronic colitis, n (\%) & $2(5)$ & $1(3)$ & $>0.01$ \\
\hline Cholelithiasis, n (\%) & $4(10)$ & $6(16)$ & $>0.01$ \\
\hline
\end{tabular}

Significant differences are marked in bold. Abbreviations: SD, standard deviation; BMI, body mass index; PeVD, pelvic venous disorder; $\mathrm{CPP}$, chronic pelvic pain; VAS, visual analogue scale; VVLE, varicose veins of the lower extremities; CVD, chronic venous disease; CEAP, Clinical-Etiological-Anatomical-Pathophysiological classification; n.a., not applicable. 


\subsection{Symptomatic Patients with PeVD}

All patients of this group had moderate to severe PVR according to DUS (reflux duration in GVs and PVs of more than $2 \mathrm{~s}$ ). Of them, 79\% had type II reflux in UVs and $26 \%$ had a combined reflux in GVs, PVs, and UVs. The $C_{P V C}$ values ranged from 1.3 to 2.8, which corresponded to grades II and III of pelvic venous congestion (Figure 2).

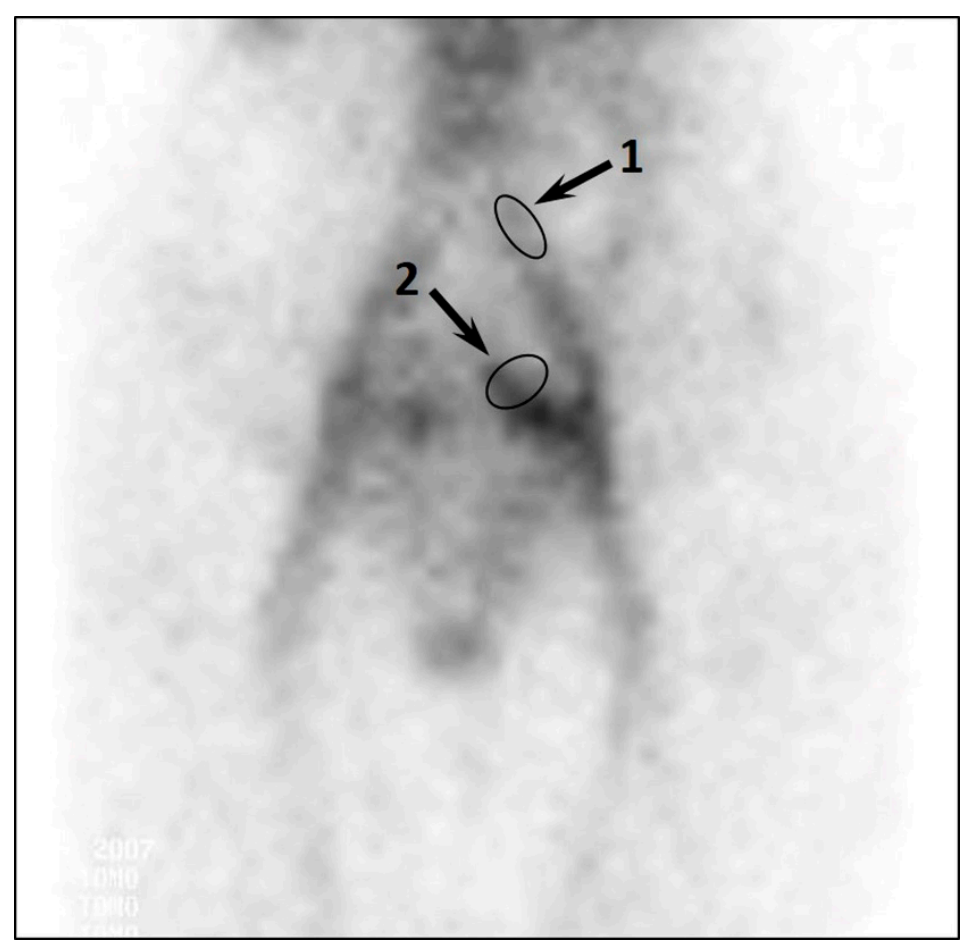

Figure 2. SPECT imaging of the pelvic veins of patient B. with symptomatic PeVD. A significant accumulation of labeled RBCs in the parametrial veins is observed. The arrows indicate the regions of interest: 1 , “common iliac vein"; 2 , "parametrial veins". $C_{\mathrm{PVC}}=1.6$

Therefore, ultrasound and radionuclide studies demonstrated a substantial impairment of venous outflow from pelvic veins, which was characterized by types II and III of PVR and $\mathrm{C}_{\mathrm{PVC}}$ values indicating grades II and III of PVC. The pathological process involved PVs and UVs in $79 \%$ of these patients, and GVs, PVs and UVs in $26 \%$ of them.

\subsection{Asymptomatic Patients with PeVD}

In asymptomatic patients, a lower rate of moderate and severe PVR (5\%) and a smaller accumulation of labeled RBCs in the pelvic venous plexuses were observed despite a significant increase in $\mathrm{PeV}$ diameters (Table 2, Figure 3). All patients showed a smaller accumulation of labeled RBCs in the parametrial and uterine veins. $\mathrm{C}_{\mathrm{PVC}}$ did not exceed 0.7-0.9, which indicates grade I of PVC. 
Table 2. Results of ultrasound and radionuclide studies in asymptomatic and symptomatic patients with PeVD $(\mathrm{N}=80)$.

\begin{tabular}{|c|c|c|c|c|c|c|}
\hline \multirow[b]{2}{*}{ Variable } & \multicolumn{3}{|c|}{ DUS } & \multicolumn{3}{|c|}{ SPECT } \\
\hline & $\begin{array}{l}\text { Without } \\
\text { Symptoms, } \\
\text { n }=38\end{array}$ & $\begin{array}{l}\text { With } \\
\text { Symptoms, } \\
\mathrm{n}=42\end{array}$ & $p$ Value * & $\begin{array}{l}\text { Without } \\
\text { Symptoms, } \\
\mathrm{n}=38\end{array}$ & $\begin{array}{l}\text { With } \\
\text { Symptoms, } \\
\mathrm{n}=42\end{array}$ & $p$ Value * \\
\hline No reflux in GVs, $\mathrm{n}(\%)$ & $36(95)$ & $31(74)$ & 0.03 & - & - & - \\
\hline $\begin{array}{c}\text { Diameter of non-refluxing GVs, mean } \pm \text { SD, mm } \\
\text { Left } \\
\text { Right }\end{array}$ & $\begin{array}{l}3.8 \pm 0.3 \\
3.2 \pm 0.2\end{array}$ & $\begin{array}{l}4.2 \pm 0.4 \\
3.5 \pm 0.3\end{array}$ & $\begin{array}{c}0.6 \\
0.43\end{array}$ & - & - & - \\
\hline Reflux in GVs, n (\%) & $2(5)$ & $11(26)$ & 0.0 & - & - & - \\
\hline $\begin{array}{c}\text { Diameter of refluxing GVs, mean } \pm \text { SD, mm } \\
\text { Left } \\
\text { Right }\end{array}$ & $\begin{array}{c}8.5 \pm 0.5 \\
\text { no }\end{array}$ & $\begin{array}{l}7.7 \pm 1.3 \\
6.8 \pm 0.5\end{array}$ & $\begin{array}{c}0.5 \\
-\end{array}$ & - & - & - \\
\hline $\begin{array}{c}\text { Duration of reflux in GVs, M [IQR], s } \\
\text { Diameter of PVs, mean } \pm \text { SD, mm } \\
\text { Reflux in PVs, } \mathrm{n}(\%) \\
\text { Duration of reflux in PVs, M [IQR], s } \\
\text { Diameter of UVs, mean } \pm \text { SD, mm } \\
\text { Reflux in UVs, n (\%) } \\
\text { Duration of reflux in UVs, M [IQR], s }\end{array}$ & $\begin{array}{l}1.0[0 ; 2.0] \\
9.5 \pm 0.9 \\
38(100) \\
1.5[1.0 ; 2.0] \\
5.5 \pm 0.6 \\
7(18) \\
1.0[1.0 ; 2.0]\end{array}$ & $\begin{array}{l}4.0[3.0 ; 5.0] \\
9.8 \pm 0.9 \\
42(100) \\
4.0[3.0 ; 5.0] \\
5.6 \pm 0.2 \\
33(79) \\
2.0[2.0 ; 3.0]\end{array}$ & $\begin{array}{c}\mathbf{0 . 0 0 8} \\
0.7 \\
\text { n.a. } \\
\mathbf{0 . 0 0 7} \\
0.87 \\
\mathbf{0 . 0 0 4} \\
\mathbf{0 . 0 4}\end{array}$ & $\begin{array}{l}- \\
- \\
- \\
- \\
- \\
-\end{array}$ & $\begin{array}{l}- \\
- \\
- \\
- \\
- \\
-\end{array}$ & $\begin{array}{l}- \\
- \\
- \\
- \\
- \\
-\end{array}$ \\
\hline $\begin{array}{c}\text { Visible GVs } \\
\text { Left GV, n (\%) } \\
\text { Right GV, n (\%) }\end{array}$ & - & - & - & $\begin{array}{l}0 \\
0\end{array}$ & $\begin{array}{l}8 \\
0\end{array}$ & - \\
\hline Excessive accumulation of RPH in PVs and UVs & - & - & - & + & +++ & - \\
\hline $\mathrm{C}_{\mathrm{PVC}}$ & - & - & - & $0.7 \pm 0.2$ & $1.9 \pm 0.4$ & 0.008 \\
\hline
\end{tabular}

Significant differences are marked in bold. Abbreviations: GV, gonadal veins; SD, standard deviation; PV, parametrial veins; UV, uterine veins; PVR, pelvic venous reflux; $\mathrm{RPH}$, radiopharmaceutical; Cpvc, coefficient of pelvic venous congestion; $\mathrm{M}$, median; IQR, interquartile range; n.a., not applicable. ${ }^{*}$ Calculated using the Student's $t$-test or Mann-Whitney U-test as appropriate. "+" is a weak accumulation of RPH. "+++" is a significant accumulation of RPH.

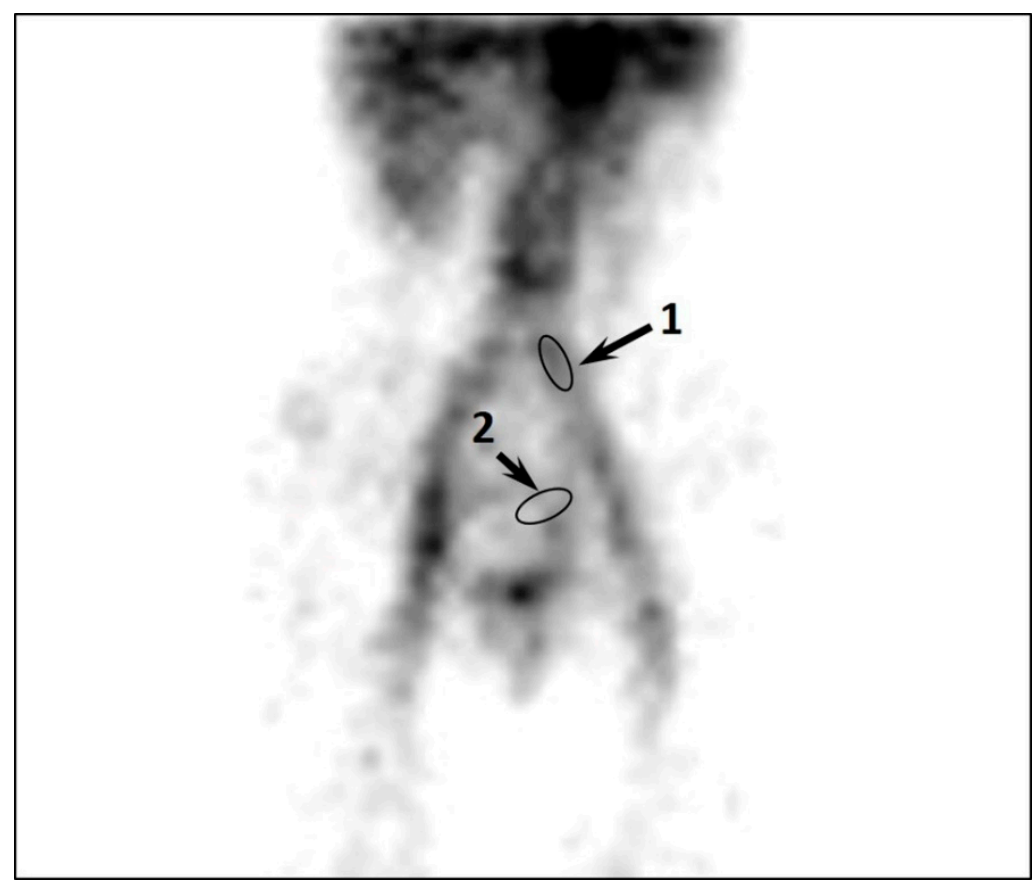

Figure 3. SPECT imaging of the pelvic veins of patient K. with asymptomatic PeVD. Low accumulation of labeled RBCs in the parametrial and uterine veins. The arrows indicate the regions of interest: 1 , "common iliac vein; 2, "parametrial" veins. $\mathrm{C}_{\mathrm{PVC}}=0.8$.

\section{Discussion}

Multiple pregnancies are among the main risk factors for the development of pelvic varicose veins (PVV) [16-18]. Pregnancy is accompanied with an increase in serum pro- 
gesterone levels by tens of times, the volume of circulating blood by $15 \%$, and the amount of blood flowing through the pelvic veins by tenfold. All of these factors can lead to PeV dilation and usually disappear after childbirth. In most women, the PeV status returns to normal, while in others the pelvic varicose veins persist and can constitute a basis for reflux development $[19,20]$. Subsequently, 60 to $76 \%$ of women with PeVD become symptomatic $[4,21-24]$. The reason for this phenomenon remains unclear $[25,26]$.

At the same time, some authors state that it is the degree of pelvic vein dilation that determines the development of PeVD symptoms and signs [27-29]. According to others, an increase in the vein diameter is not a significant factor in the onset of clinical manifestations of PeVD, and the main mechanism contributing to the onset of CPP is the presence of reflux in PeVs and its duration $[4,7,11,30,31]$. Routine clinical practice shows that PeV dilation is quite a common observation; however, it is accompanied by PeVD symptoms in no more than a third of patients.

In the present study, a comparative analysis to identify relationships of clinical manifestations of PeVD with PeV diameters, PVR, and severity of blood deposition in the pelvic collecting pools was performed. PeV diameters were found to be similar in the symptomatic versus asymptomatic course of the disease (GVs: $7.7 \pm 1.3$ vs. $8.5 \pm 0.5 \mathrm{~mm}$, respectively, $p=0.56$; PVs: $9.8 \pm 0.9$ vs. $9.5 \pm 0.9 \mathrm{~mm}$, respectively, $p=0.75$; and UVs: $5.6 \pm 0.2$ vs. $5.5 \pm 0.6 \mathrm{~mm}$, respectively, $p=0.87$ ). In addition, SPECT of the pelvic veins with in vivo labeled RBCs showed that with the same dilation of PeVs according to DUS data, the $\mathrm{C}_{\mathrm{PVC}}$ was significantly higher in patients with PeVD symptoms than in asymptomatic patients $(1.9 \pm 0.4$ vs. $0.7 \pm 0.2$, respectively, $p=0.008)$. Linear correlation analysis revealed a strong positive relationship (Pearson's $r=0.78 ; p=0.007$ ) between the presence of pelvic pain and the PVR duration in patients with PeVD. On the contrary, the linear correlation between $\mathrm{PeV}$ diameters and the presence of clinical manifestations of PeVD was weak $(\mathrm{r}=0.18)$, which indicates a minor influence of this factor.

These findings suggest that in symptomatic patients, the pathological process involves a greater number of refluxing pelvic veins, as compared to asymptomatic patients (combined reflux in GVs, PVs and UVs in 26\% vs. 5\%, respectively, $p=0.007$; combined reflux in PVs and UVs in $79 \%$ vs. $18 \%$, respectively, $p=0.004$ ). Symptomatic patients had PVR of types II or III (>2 s), while asymptomatic patients had PVR of type I (duration less than $\leq 2 \mathrm{~s}$ ). The reflux duration was also longer in symptomatic versus asymptomatic patients (median and interquartile range: 4.0 [3.0; 5.0] vs. $1.0[0 ; 2.0]$ s for GVs, $p=0.008$; $4.0[3.0 ; 5.0]$ vs. $1.1[1.0 ; 2.0] \mathrm{s}$ for PVs, $p=0.007$; and $2.0[2.0 ; 3.0]$ vs. $1.0[1.0 ; 2.0]$ s for UVs, $p=0.04)$. These findings suggest that diameters or degree of dilation of the pelvic veins do not play a significant role in the development of clinical manifestations of PeVD and are not appropriate for its diagnosis. On the contrary, the PVR duration and its pattern in the pelvic veins should be considered as predictors of the development of symptomatic forms of PeVD.

This study had limitations due to the small number of patients and its open (nonrandomized) retrospective nature. Despite the conclusive results of our research, future studies are warranted to confirm our findings in larger cohorts.

\section{Conclusions}

Findings from this study indicate that the leading factors in the development of symptomatic forms of PeVD are the duration of pelvic venous reflux, its prevalence in the pelvic veins, and blood deposition in the pelvic venous plexuses. The diameter of pelvic veins is not different in patients with symptomatic and asymptomatic PeVD, has no significant effect on the presence and severity of pelvic pain, and cannot be used as a diagnostic criterion. Duplex ultrasound serves as an accurate and objective method for assessing the status of pelvic veins, and its data can provide guidance for further examination of patients and confirm the necessity of additional radiation diagnostic tests. 


\begin{abstract}
Author Contributions: Conceptualization and design: S.G., A.K. Analysis and interpretation: S.G., A.K., N.M., O.E., A.G. Data collection: S.G., A.K., O.E., N.M. Writing the article: S.G., A.K., N.M., O.E., A.G. Critical revision of the article: S.G., A.K., N.M., O.E., A.G. Final approval of the article: S.G., A.K., N.M., O.E., A.G. Statistical analysis: N.M., A.G., O.E. All authors have read and agreed to the published version of the manuscript.
\end{abstract}

Funding: This research received no external funding.

Institutional Review Board Statement: The study was performed in accordance with the guidelines of the Declaration of Helsinki and approved by the Ethics Committee of the Pirogov Russian National Research Medical University (Protocol No. 206; approved on 22 March 2021).

Informed Consent Statement: Informed consent was obtained from all subjects involved in the study.

Conflicts of Interest: The authors declare no conflict of interest.

\title{
References
}

1. El-Minawi, A.M. Pelvic varicosities and pelvic congestion syndrome. In Pelvic Pain: Diagnosis and Management; Howard, F.M., Perry, C.P., Carter, J.E., El-Minawi, A.M., Eds.; Lippincott, Williams \& Wilkins: Philadelphia, PA, USA, 2000; pp. 171-183.

2. Antignani, P.L.; Lazarashvili, Z.; Monedero, J.L.; Ezpeleta, S.Z.; Whiteley, M.S.; Khilnani, N.M.; Meissner, M.H.; Wittens, C.H.; Kurstjens, R.L.; Belova, L.; et al. Diagnosis and treatment of pelvic congestion syndrome: UIP consensus document. Int. Angiol. 2019, 38, 265-283. [CrossRef]

3. Champaneria, R.; Shah, L.; Moss, J.; Gupta, J.K.; Birch, J.; Middleton, L.J.; Daniels, J.P. The relationship between pelvic vein incompetence and chronic pelvic pain in women: Systematic reviews of diagnosis and treatment effectiveness. Health Technol. Assess. 2016, 20, 1-108. [CrossRef]

4. Gavrilov, S.; Moskalenko, Y.P.; Mishakina, N.Y.; Efremova, O.I.; Kulikov, V.M.; Grishenkova, A.S. Stratification of pelvic venous reflux in patients with pelvic varicose veins. J. Vasc. Surg. Venous Lymphat. Disord. 2021, 9, 1417-1424. [CrossRef]

5. Gavrilov, S.G.; Krasavin, G.V.; Mishakina, N.Y.; Efremova, O.I.; Zolotukhin, I.A. The effect of venoactive drug therapy on the development and severity of post-embolization syndrome in endovascular Interventions on the gonadal veins. J. Pers. Med. 2021, 11, 521. [CrossRef] [PubMed]

6. Ganeshan, A.; Upponi, S.; Hon, L.-Q.; Uthappa, M.C.; Warakaulle, D.R.; Uberoi, R. Chronic pelvic pain due to pelvic congestion syndrome: The role of diagnostic and interventional radiology. Cardiovasc. Interv. Radiol. 2007, 30, 1105-1111. [CrossRef]

7. Dos Santos, S.J.; Holdstock, J.M.; Harrison, C.C.; Lopez, A.J.; Whiteley, M.S. Ovarian Vein Diameter Cannot Be Used as an Indicator of Ovarian Venous Reflux. Eur. J. Vasc. Endovasc. Surg. 2015, 49, 90-94. [CrossRef] [PubMed]

8. Whiteley, A.M.; Taylor, D.C.; Dos Santos, S.J.; Whiteley, M.S. Pelvic venous reflux is a major contributory cause of recurrent varicose veins in more than a quarter of women. J. Vasc. Surg. Venous Lymphat. Disord. 2014, 2, 411-415. [CrossRef]

9. Whiteley, M.S.; Dos Santos, S.J.; Harrison, C.C.; Holdstock, J.M.; Lopez, A.J. Transvaginal duplex ultrasonography appears to be the gold standard investigation for the haemodynamic evaluation of pelvic venous reflux in the ovarian and internal iliac veins in women. Phlebology 2015, 30, 706-713. [CrossRef]

10. Dos Santos, S.J.; Holdstock, J.M.; Harrison, C.C.; Whiteley, M.S. Long-term results of transjugular coil embolisation for pelvic vein reflux -Results of the abolition of venous reflux at 6-8 years. Phlebology 2016, 31, 456-462. [CrossRef] [PubMed]

11. Whiteley, M.S. Objective measurements of pelvic venous reflux and stratification of severity of venous reflux in pelvic congestion syndrome due to pelvic venous reflux. Curr. Med. Res. Opin. 2019, 33, 2089-2095. [CrossRef]

12. Szary, C.; Wilczko, J.; Zawadzki, M.; Grzela, T. Hemodynamic and Radiological Classification of Ovarian Veins System Insufficiency. J. Clin. Med. 2021, 10, 646. [CrossRef]

13. Ananthan, K.; Onida, S.; Davies, A.H. Nutcracker syndrome: An update on current diagnostic criteria and management guidelines. Eur. J. Vasc. Endovasc. Surg. 2017, 53, 886-894. [CrossRef] [PubMed]

14. Velasquez, C.A.; Saeyeldin, A.; Zafar, M.A.; Brownstein, A.J.; Erben, Y. A systematic review on management of nutcracker syndrome. J. Vasc. Surg. Venous Lymphat. Disord. 2018, 6, 271-278. [CrossRef]

15. Gavrilov, S.G.; Karalkin, A.V.; Turischeva, O.O. Compression treatment of pelvic congestion syndrome. Phlebology 2018, 33, 418-424. [CrossRef] [PubMed]

16. Stones, R.W. Chronic pain in women: New perspectives on pathophysiology and management. Reprod. Med. Rev. 2000, 8, 229-240. [CrossRef]

17. Daniels, J.P.; Khan, K.S. Chronic pelvic pain in women. BMJ 2010, 341, c4834. [CrossRef]

18. Phillips, D.; Deipolyi, A.R.; Hesketh, R.L.; Midia, M.; Oklu, R. Pelvic congestion syndrome: Etiology of pain, diagnosis, and clinical management. J. Vasc. Interv. Radiol. 2014, 25, 725-733. [CrossRef]

19. Gavrilov, S.G.; Vasiliev, A.; Moskalenko, Y.; Mishakina, N. Diagnostic value of pelvic venography in female patients with pelvic varicose veins and vulvar varicosities. Int. Angiol. 2020, 39, 452-460. [CrossRef]

20. Gloviczki, P.; Comerota, A.J.; Dalsing, M.C.; Eklof, B.G.; Gillespie, D.L.; Gloviczki, M.L.; Lohr, J.M.; McLafferty, R.B.; Meissner, M.H.; Murad, M.H.; et al. The care of patients with varicose veins and associated chronic venous diseases: Clinical practice guidelines of the Society for Vascular Surgery and the American Venous Forum. J. Vasc. Surg. 2011, 53, 2S-48S. [CrossRef] 
21. Herrera-Betancourt, A.L.; Villegas-Echeverri, J.D.; Lopez-Jaramillo, J.D.; Lopez-Isanoa, J.D.; Estrada-Alvarez, J.M. Sensitivity and specificity of clinical findings for the diagnosis of pelvic congestion syndrome in women with chronic pelvic pain. Phlebology 2018, 33, 303-308. [CrossRef]

22. Asciutto, G.; Mumme, A.; Asciutto, K.C.; Geier, B. Pelvic vein incompetence influences pain levels in patients with lower limb varicosity. Phlebology 2010, 25, 179-183. [CrossRef]

23. Khilnani, N.M.; Meissner, M.H.; Learman, L.A.; Gibson, K.D.; Daniels, J.P.; Winokur, R.S.; Marvel, R.P.; Machan, L.; Venbrux, A.C.; Tu, F.F.; et al. Research priorities in pelvic venous disorders in women: Recommendations from a multidisciplinary research consensus panel. J. Vasc. Interv. Radiol. 2019, 30, 781-789. [CrossRef]

24. Ignacio, E.A.; Dua, R.; Sarin, S.; Amy Soltes Harper Yim, D.; Mathur, V.; Venbrux, A.C. Pelvic congestion syndrome: Diagnosis and treatment. Semin. Interv. Radiol. 2008, 25, 361-368. [CrossRef]

25. Gavrilov, S.G.; Vasilieva, G.Y.; Vasiliev, I.M.; Efremova, O.I. Calcitonin gene-related peptide and substance P as predictors of venous pelvic pain. Acta Nat. 2019, 11, 88-92. [CrossRef]

26. Gavrilov, S.G.; Vassilieva, G.Y.; Vasilev, I.M.; Grishenkova, A.S. The role of vasoactive neuropeptides in the genesis of venous pelvic pain: A review. Phlebology 2020, 35, 4-9. [CrossRef] [PubMed]

27. White, J.V. Moving toward more appropriate care for women with pelvic, labial, or perineal venous disease. J. Vasc. Surg. Venous Lymphat. Disord. 2017, 5, 475-476. [CrossRef]

28. Gibson, K.; Minjarez, R.; Ferris, B.; Neradilek, M.; Wise, M.; Stoughton, J.; Meissner, M. Clinical presentation of women with pelvic source varicose veins in the perineum as a first step in the development of a disease-specific patient assessment tool. $J$. Vasc. Surg. Venous Lymphat. Disord. 2017, 5, 493-499. [CrossRef] [PubMed]

29. White, A.M.; Holdstock, J.M. Ultrasound assessment of pelvic venous reflux. Indian J. Vasc. Endovasc. Surg. 2018, 5, $234-243$. [CrossRef]

30. Greiner, M.; Gilling-Smith, G.L. Leg varices originating from the pelvis: Diagnosis and treatment. Vascular 2007, 15, 70-78. [CrossRef]

31. Malgor, R.D.; Adrahtas, D.; Spentzouris, G.; Gasparis, A.P.; Tassiopoulos, A.K.; Labropoulos, N. The role of duplex ultrasound in the workup of pelvic congestion syndrome. J. Vasc. Surg. Venous Lymphat. Disord. 2014, 2, 34-38. [CrossRef] [PubMed] 